ORIGINAL ARTICLE

\title{
Comparison of aprepitant and dexamethasone versus metoclorpramide and dexamethasone for prevention of post-operative nausea and vomiting in patients undergoing laparoscopic cholecystectomy.
}

\author{
Zerwah Muhammad Qayum ${ }^{1}$, Aftab Hussain $^{2}$, Muhammad Akram ${ }^{3}$, Muhammad Asif Saleem ${ }^{4}$, Rehana Feroze $^{5}$, Faisal Wahid $^{6}$
}

Article Citation: Qayum ZM, Hussain A, Akram M, Saleem MA, Feroze R, Wahid F. Comparison of aprepitant and dexamethasone versus metoclorpramide and dexamethasone for prevention of post-operative nausea and vomiting in patients undergoing laparoscopic cholecystectomy. Professional Med J 2022; 29(1):7-12. https://doi.org/10.29309/TPMJ/2022.29.01.6604

ABSTRACT... Objective: To compare the efficacy of aprepitant and dexamethasone versus metoclopramide and dexamethasone combination in prevention of post-operative nausea and vomiting in females undergoing laparoscopic cholecystectomy. Study Design: Prospective Comparative study. Setting: Department of Anesthesia, CMH Lahore. Period: October 2019 to April 2020. Material \& Methods: A total of 140 female patients planned for laparoscopic cholecystectomy under general anesthesia, of age ranges from 35-65 years and ASA classification I and II were recruited for the study and were divided into two equal groups. In group $A(n=70)$, patients were given oral aprepitant $80 \mathrm{mg}$ with once sip of water one hour prior to induction and dexamethasone $8 \mathrm{mg}$ upon induction. In group $M(n=70)$, patients were given a placebo one hour prior to induction and intravenous metoclopramide $10 \mathrm{mg}$ and dexamethasone $8 \mathrm{mg}$ upon induction. Results: Age range in this study was from 37 to 65 years with mean age of $46.82 \pm 7.29$ years. The mean age of patients in group A was $45.73 \pm 6.77$ years and in group $M$ was $47.91 \pm 7.66$ years with $p$-value of 0.076 . In our study, significant difference was found between the efficacy of two groups of drugs. The efficacy of aprepitant and dexamethasone was found in $62(88.57 \%)$ patients, while with metoclopramide and dexamethasone, it was found in 51 (72.86\%) patients with p-value of 0.031 . Conclusion: it is concluded that aprepitant and dexamethasone combination has higher efficacy as compared to metoclorpromide and dexamethasone in prevention of post-operative nausea and vomiting in elective laparoscopic cholecystectomy.

Key words: $\quad$ Aprepitant, Dexamethasone, Laparoscopic Cholecystectomy, Post-Operative Nausea and Vomiting.

\section{INTRODUCTION}

Post-operative nausea and vomiting (PONV) is one of the most common adverse effects of general anesthesia and surgery, particularly among women following laparoscopy due to pneumoperitoneum created during surgery. ${ }^{1-2}$ PONV may cause pain, discomfort, dehydration, aspiration pneumonia, electrolyte imbalance, hemorrhage, surgical wound dehiscence, which can increase the morbidity, mortality, cost and prolonged hospital stay. The prevalence rate of PONV is $30-80 \%$, but however this rate varies according to surgical and anesthetic factors. ${ }^{3-4}$

\section{PONV prophylaxis is used before general} anesthesia to prevent emesis and promote early recovery. Several drugs have been used for this, such as anti-histamines, anti-cholinergics and dopamine-receptor antagonists. A corticosteroid hormone, dexamethasone, also has some antiemetic property. Newer class of drugs such as serotonin receptor antagonists and neurokinin-1 (NK1) receptor antagonists have better safety profile and are more effective than traditional drugs. ${ }^{5}$

Metoclopramide, a dopamine 2 receptor antagonist, is widely used in PONV prophylaxis. Metoclopramide is an effective anti-emetic but has some unwanted extrapyramidal side effects such as dystonia, akathisia, tremors, bradykinesia and tardive dyskinea. ${ }^{6}$
1. MBBS, Resident Anesthesiologist, CMH Lahore.

2. MBBS, FCPS, Senior Registrar Anesthesia, CMH Lahore.

3. MBBS, MCPS, FCPS, Assistant Professor Anesthesia, CMH Lahore.

4. MBBS, MCPS, FCPS, Senior Registrar Anesthesia, CMH Lahore.

5. MBBS, MCPS, FCPS, Assistant Professor Anesthesia, CMH Lahore.

6. MBBS, FCPS, Assistant Professor Anesthesia, CMH Lahore.

\author{
Correspondence Address: \\ Dr. Zerwah Muhammad Qayum \\ Department of Anesthesiologist \\ $\mathrm{CMH}$ Lahore. \\ drzerwahmuhammad@gmail.com
}

Article received on:

$21 / 05 / 2021$ Accepted for publication: 
Dexamethasone, a known anti-emetic, is highly effective in the prevention of emesis caused by cancer chemotherapy. Animal studies have proved that glucocorticoid receptors are present on the nucleus of solitary tract which mediate the anti-emetic property of Dexamethasone. Dexamethasone is more effective anti-emetic when used in combination with other anti-emetics than being used alone. ${ }^{7}$

The NK1 receptors present in the vagal afferent of gastrointestinal tract and central nervous system vomiting reflex pathway, produce conditions of nausea and vomiting due to activation by Substance P. ${ }^{8}$ Aprepitant is a NK1 receptor antagonist provides its anti-emetic activity by suppressing the above mentioned pathways. Other newer NK1 receptor antagonists such as fosaprepitant, rolapitant and casopitant have also been introduced and are found to be effective anti-emetics. $^{9}$

The study was aimed at determining the efficacy of two combinations of antiemetics ie: aprepitant and dexamethasone versus metoclorpromide and dexamethasone in preventing PONV in females undergoing elective laparoscopic cholecystectomy. No such study has been done in our general population and data from international literature is scarce, and their results cannot be generalized on all population due to different genetic makeup. Therefore, we had planned to compare the effectiveness of aprepitant and dexamethasone versus metoclorpromide and dexamethasone for prevention of PONV. Our study will pave the way in selecting the right drug combination to prevent PONV in our general population.

\section{MATERIAL \& METHODS}

This prospective comparative study was conducted in anesthesia department $\mathrm{CMH}$ Lahore over a period of six months from 1st October 2019 to 30th April 2020 the study was approved by ethical committee (711/2019/Trg/Adm). Sample size was calculated with power of $80 \%$, level of significance $5 \%, \mathrm{P} 1$ as 16 . $3 \%{ }^{10}, \mathrm{P} 2$ as $36.7 \%{ }^{10}$, the sample size calculator determined that 70 subjects were required for study in each group.
Hence the total number of patients required for the study was determined to be 140 . Nonprobability consecutive sampling technique was followed in this study. Female patients with age range between 35 to 65 years planned for elective laparoscopic cholecystectomy with American Society of Anesthesiologists (ASA) classification of I and II were included in this study. Patients with history of chronic nausea and vomiting, presence of nausea and vomiting 24 hours before anesthesia, body mass index $(\mathrm{BMI})>35$ $\mathrm{kg} / \mathrm{m}^{2}$, menstruating and pregnant patients were excluded for the study. Patients with history of substance abuse, smoking, motion sickness and allergic to drugs under study were also excluded from the study.

One hundred and forty female patients admitted from outdoor patient department for laparoscopic cholecystectomy were evaluated for general anesthesia by a resident anesthesiologist who was blinded to the study. Every third patient fulfilling the inclusion and exclusion criteria were selected for the study. Informed consent was taken from the patients, ensuring confidentiality and that no risk was involved in using aprepitant and dexamethasone versus metoclorpromide and dexamethasone during the study. Demographic data of patients (age and BMI) was noted on the proforma.

Patients were taken to the operation theatre in the presence of resident anesthesiologist and intravenous drugs were prepared and given by the same anesthesiologist. Patients were kept nil per oral for eight hours. In group $A(n=70)$, patients were given oral aprepitant $80 \mathrm{mg}$ with once sip of water, one hour prior to induction and dexamethasone $8 \mathrm{mg}$ upon induction and in group $M(n=70)$, patients were given a placebo one hour prior to induction and intravenous dexamethasone $8 \mathrm{mg}$ and metoclopramide $10 \mathrm{mg}$ upon induction.

In operation theatre, an 18-guage intravenous cannula was passed and standard monitoring was attached, that is pulse-oximeter, noninvasive blood pressure, temperature and electrocardiogram. Premedication included intravenous midazolam 
$0.02 \mathrm{mg} / \mathrm{kg}$, nalbuphine $0.1 \mathrm{mg} / \mathrm{kg}$ and ringer's lactate $10 \mathrm{ml} / \mathrm{kg}$ as maintenance fluid. Induction of anesthesia was done with intravenous propofol $2 \mathrm{mg} / \mathrm{kg}$ and muscle relaxation was achieved with intravenous atracurium $0.5 \mathrm{mg} /$ $\mathrm{kg}$ and patient was intubated with $7.0 \mathrm{~mm}$ cuffed endotracheal tube (ETT). Correct ETT placement was confirmed with bilateral chest auscultation and end-tidal carbon dioxide concentration. Non-invasive blood pressure was measured every 3 minutes. Anesthesia was maintained with inhalational isoflurane in a mixture of oxygen and air, maintaining minimum alveolar concentration (MAC) between 1.2 to 2.0. Intravenous atracurium was repeated, if required, to maintain muscle relaxation during the procedure.

At the end of the procedure, isoflurane was discontinued and neuromuscular blockade was reversed with intravenous neostigmine $0.04 \mathrm{mg} /$ $\mathrm{kg}$ and glycopyrrolate $0.01 \mathrm{mg} / \mathrm{kg}$. ETT was removed when the patient was fully awake and breathing spontaneously. For local anesthesia at the site of port insertion, $0.125 \%$ Bupivacaine, was injected. After extubation, patient was shifted to post-anesthesia care unit (PACU). Rescue antiemetic in the form of intravenous Ondansetron $8 \mathrm{mg}$ was given if patient experienced nausea for more than 15 mins or persistent vomiting.

Datawas analyzed with statistical analysis program
(IBM-SPSS version 24). Analysis was done to compare proportion of both groups. Frequency and percentage of PONV were computed. Mean \pm SD was presented for quantitative variables like age, weight, height and BMl. Chi-square test was applied to compare both groups in terms of PONV with $p$-value $\leq 0.05$ taken as significant.

\section{RESULTS}

Age range in this study was from 37 to 65 years with mean age of $46.82 \pm 7.29$ years. The mean age of patients in group A was $45.73 \pm 6.77$ years and in group $M$ was $47.91 \pm 7.66$ years with $p$-value of 0.076 . Distribution of patients according to ASA status is shown in Table-l.

The BMl range in this study was from 23 to 34 $\mathrm{kg} / \mathrm{m}^{2}$ with mean BMl of $28.73 \mathrm{~kg} / \mathrm{m}^{2}$. The mean $\mathrm{BMl}$ of patients in group A was $29.11 \pm 2.47 \mathrm{~kg} /$ $\mathrm{m}^{2}$ and in group $M$ was $28.34 \pm 2.71 \mathrm{~kg} / \mathrm{m}^{2}$ with a p-value of 0.08 .

In our study, efficacy of aprepitant and dexamethasone was found in 62 patients, while with metoclopramide and dexamethasone, it was found in 51 patients. Details are shown in Table-II.

\section{DISCUSSION}

PONV is one of the frequently encountered problems related to anesthesia and surgery which occurs in immediate post-operative period. ${ }^{11,12}$

\begin{tabular}{|l|c|c|c|c|c|c|}
\hline & \multicolumn{2}{|c|}{ Group A $(\mathbf{n = 7 0 )}$} & \multicolumn{2}{c|}{ Group B $(\mathbf{n = 7 0 )}$} & \multicolumn{2}{c|}{ Total $(\mathbf{n = 1 4 0 )}$} \\
\hline \multirow{2}{*}{ ASA } & $\begin{array}{c}\text { No. of } \\
\text { patients }\end{array}$ & \%age & $\begin{array}{c}\text { No. of } \\
\text { patients }\end{array}$ & \%age & $\begin{array}{c}\text { No. of } \\
\text { patients }\end{array}$ & \%age \\
\hline I & 20 & 28.57 & 27 & 38.57 & 47 & 33.57 \\
\hline II & 50 & 71.43 & 43 & 61.43 & 93 & 66.43 \\
\hline
\end{tabular}

Table-I. Distribution of patients according to ASA status. $(n=140)$

\begin{tabular}{|l|c|c|c|c|c|}
\hline & \multicolumn{2}{|c|}{} & \multicolumn{2}{|c|}{ Group A $(\mathbf{n = 7 0 )}$} & \multicolumn{2}{c|}{ Group B (n=70) } \\
\hline \multirow{2}{*}{ Efficacy } & No. & \%age & No. & \%age \\
\hline & Yes & 62 & 88.57 & 51 & 72.86 \\
\cline { 2 - 6 } & No & 08 & 11.43 & 19 & 27.14 \\
\hline
\end{tabular}


Without any prophylactic medication, the incidence of PONV can vary from $20 \%$ to $30 \%$ in the general surgical population and the incidence may rise to up to $80 \%$ in high-risk patients. ${ }^{13,14}$ Various antiemetic drugs have been used for the prophylaxis and treatment of PONV. Single drug can significantly lower the incidence of PONV. However, many researchers emphasize that the combination of two antiemetic drugs can further decrease the incidence of PONV compared to single-agent treatment especially for the high-risk patients. ${ }^{15}$

In our study we found out that combination of metoclorpromide and dexamethasone failed to prevent PONV in 27.14\%. Similar results were observed by Alkaissi $A$ et al. in their study. ${ }^{16}$ In our study it was observed that combination of aprepitant and dexamethasone failed to prevent PONV in $11.43 \%$ patients. In a similar study conducted by Bilgen $S$ et al. found out that same combination failed to prevent PONV in $31 \%$ patients which is quite a big number. ${ }^{17} \mathrm{Habib}$ AS et al. observed in their study that combination of aprepitant and dexamethasone proved to be more effective than the ondansetron and dexamethasone combination for the prevention of PONV in patients who underwent craniotomy under general anaesthesia. ${ }^{18}$

In our study, efficacy of aprepitant and dexamethasone and Aprepitant was found in $62(88.57 \%)$ patients and metoclorpramide and dexamethasonewas found in 51 (72.86\%) patients. In a study done in 2017, the effect of aprepitant along with ondansetron and dexamethasone was compared to ondansetron and dexamethasone alone for attenuation in PONV after laparoscopic surgery. It was found that the incidence of PONV in the aprepitant group was less than the control hence no rescue antiemetic was required in the first 24 hours following surgery in the aprepitant group. ${ }^{19}$

No such local study has been conducted with these combinations of antiemetics. However a study conducted by Akram $\mathrm{M}$ et al. concluded that aprepitant significantly decreases the incidence of PONV and requirements of post-operative rescue antiemetics. ${ }^{20}$

PONV is a very a very common complication of anesthesia and surgery. It is very distressing for the patients and carries many risks. Aprepitant is a newer antiemetic drug with promising results. Further studies are recommended to be carried out to find out the optimum dosage and time to be given pre-operatively.

\section{CONCLUSION}

This study concluded that aprepitant and dexamethasone combination has higher efficacy as compared to metoclorpromide and dexamethasone in prevention of post-operative nausea and vomiting in elective laparoscopic cholecystectomy. So, we recommend that dexamethasone and metoclopramide with aprepitant should be used routinely in patients undergoing surgery under general anesthesia in order to reduce the post-operative nausea and vomiting.

\section{Copyright $(28$ July, 2021.}

\section{REFERENCES}

1. Yilmaz G, Akca A, Kiyak H, Salihoglu Z. Elevation in optic nerve sheath diameter due to the pneumoperitoneum and Trendelenburg is associated to postoperative nausea, vomiting and headache in patients undergoing laparoscopic hysterectomy. Minerva Anestesiologica. 2020; 86(3):270-276. DOI: 10.23736/s0375-9393.19.13920-x.

2. Besir A, Tugcugil E. Comparison of different end-tidal carbon dioxide levels in preventing postoperative nausea and vomiting in gynaecological patients undergoing laparoscopic surgery. Journal of Obstetrics and Gynaecology. 2020; 1-8. doi:10.1080/0 1443615.2020.1789961.

3. Shaikh SI, Nagarekha D, Hegade G, Marutheesh M. Postoperative nausea and vomiting: A simple yet complex problem. Anesthesia, essays and researches. 2016; 10(3):388-396. https://doi.org/10.4103/02591162.179310 .

4. Lee S, Lee S, Kim S, Ok S, Kim S, Park S et al. The effect of aprepitant for the prevention of postoperative nausea and vomiting in patients undergoing gynecologic surgery with intravenous patient controlled analgesia using fentanyl: Aprepitant plus ramosetron vs ramosetron alone. Korean $J$ Anesthesiol. 2012; 63(3): 221. 
5. Therneau IW, Martin EE, Sprung J, Kellogg TA, Schroeder DR, Weingarten TN. Correction to: The role of Aprepitant in prevention of postoperative nausea and vomiting after bariatric surgery. Obesity Surgery. 2019; 29(4):1448-1448. doi:10.1007/s11695019-03767-x.

6. Bauer M, Bamminger K, Pichler V, Weber M, Binder $S$, Maier $\square$ Salamon $A$ et al. Impaired clearance from the brain increases the brain exposure to Metoclopramide in elderly subjects. Clinical Pharmacology \& Therapeutics. 2020; 109(3):754-761. doi:10.1002/cpt.2052.

7. Liu J, Li H, Zhang J, Dong X, Xue J, Shi X et al. Dexamethasone or combined with others for postoperative nausea and vomiting in children: A systematic review. Asian Journal of Surgery. 2020; 43(9):873-879. doi:10.1016/j.asjsur.2019.11.012.

8. Okafor $D$, Kaye $A D$, Kaye $R J$, Urman $R D$. The role of neurokinin-1 (substance $P$ ) antagonists in the prevention of postoperative nausea and vomiting. Journal of anaesthesiology, clinical pharmacology. 2017; 33(4):441-445. https://doi.org/10.4103/09709185.222511 .

9. Rapoport B, Smit T. Clinical pharmacology of neurokinin-1 receptor antagonists for the treatment of nausea and vomiting associated with chemotherapy. Expert Opinion on Drug Safety. 2017; 16(6):697-710. doi:10.1080/14740338.2017.1325868.

10. Tabari $M$, Shabahang $H$, Tavasoli $A$, Abbaspour $H$, Alipour M. Comparative study of the effectiveness of ondansetron, metoclopramide and low dose dexamethasone to prevent postoperative nausea and vomiting in females who undergo laparoscopic cholecystectomy. Women's Health Bull. 2014; 1(3): e22661. doi: 10.17795/whb-2266.

11. Thomas JS, Maple IK, Norcross W, Muckler VC. Preoperative risk assessment to guide prophylaxis and reduce the incidence of postoperative nausea and vomiting. Journal of PeriAnesthesia Nursing. 2019; 34(1):74-85. doi:10.1016/j.jopan.2018.02.007.

12. Jin Z, Gan TJ, Bergese SD. Prevention and treatment of postoperative nausea and vomiting (PONV): A review of current recommendations and emerging therapies. Therapeutics and clinical risk management. 2020; 16(1):1305-1317. https://doi.org/10.2147/TCRM. S256234.
13. Apfel CC, Läärä E, Koivuranta M, Greim CA, Roewer N. A simplified risk score for predicting postoperative nausea and vomiting: Conclusions from crossvalidations between two centers. Anesthesiology. 1999; 91(3):693-700. doi:10.1097/00000542199909000-00022.

14. Yi MS, Kang H, Kim MK, Choi G, Park Y, Baek CW et al. Relationship between the incidence and risk factors of postoperative nausea and vomiting in patients with intravenous patient-controlled analgesia. Asian Journal of Surgery. 2018; 41(4):301-306. doi:10.1016/j. asjsur.2017.01.005.

15. Kranke P, Meybohm P, Diemunsch P, Eberhart LH. Riskadapted strategy or universal multimodal approach for PONV prophylaxis? Best Practice \& Research Clinical Anaesthesiology. 2020; 34(4):721-734. doi:10.1016/j.bpa.2020.05.003.

16. Alkaissi A, Dwaikat $M$, Almasri N. Dexamethasone, metoclopramide, and their combination for the prevention of postoperative nausea and vomiting in female patients with moderate-to-high risk for ponv undergoing laparoscopic surgery. Journal of Evolution of Medical and Dental Sciences. 2017; 6(75):5353-5359. doi:10.14260/jemds/2017/1162.

17. Bilgen S, Kızılcık N, Haliloğlu M, Yıldırım G, Kaspar EÇ, Köner Ö. Effect of the dexamethasone-ondansetron combination versus dexamethasone-aprepitant combination to prevent postoperative nausea and vomiting. Turkish journal of anaesthesiology and reanimation. 2018; 46(5):373-380. https://doi. org/10.10.5152/TJAR.2018.53179.

18. Habib AS, Keifer JC, Borel CO, White WD, Gan TJ. A comparison of the combination of aprepitant and dexamethasone versus the combination of ondansetron and dexamethasone for the prevention of postoperative nausea and vomiting in patients undergoing craniotomy. Anesth Analg. 2011; 112(4):813-818. doi:10.1213/ANE.0b013e3181ff47e2.

19. Hussein $\mathrm{MM}$, Mostafa $\mathrm{RH}$. Aprepitant for attenuation of postoperative nausea and vomiting with a decrease in postoperative analgesic needs after laparoscopic surgery. Ain-Shams J Anesthesiol. 2017; 10(1):144-8 doi:10.410.

20. Akram M, Bajwa S, A, Hussain A, Safdar CA, Khan U. The efficacy of aprepitant (nk-1 receptor antagonist) as prophylaxis for postoperative nausea and vomiting. PAFMJ. 2020; 70(2):281-85. Retrieved from https://www. pafmj.org/index.php/PAFMJ/article/view/4174. 


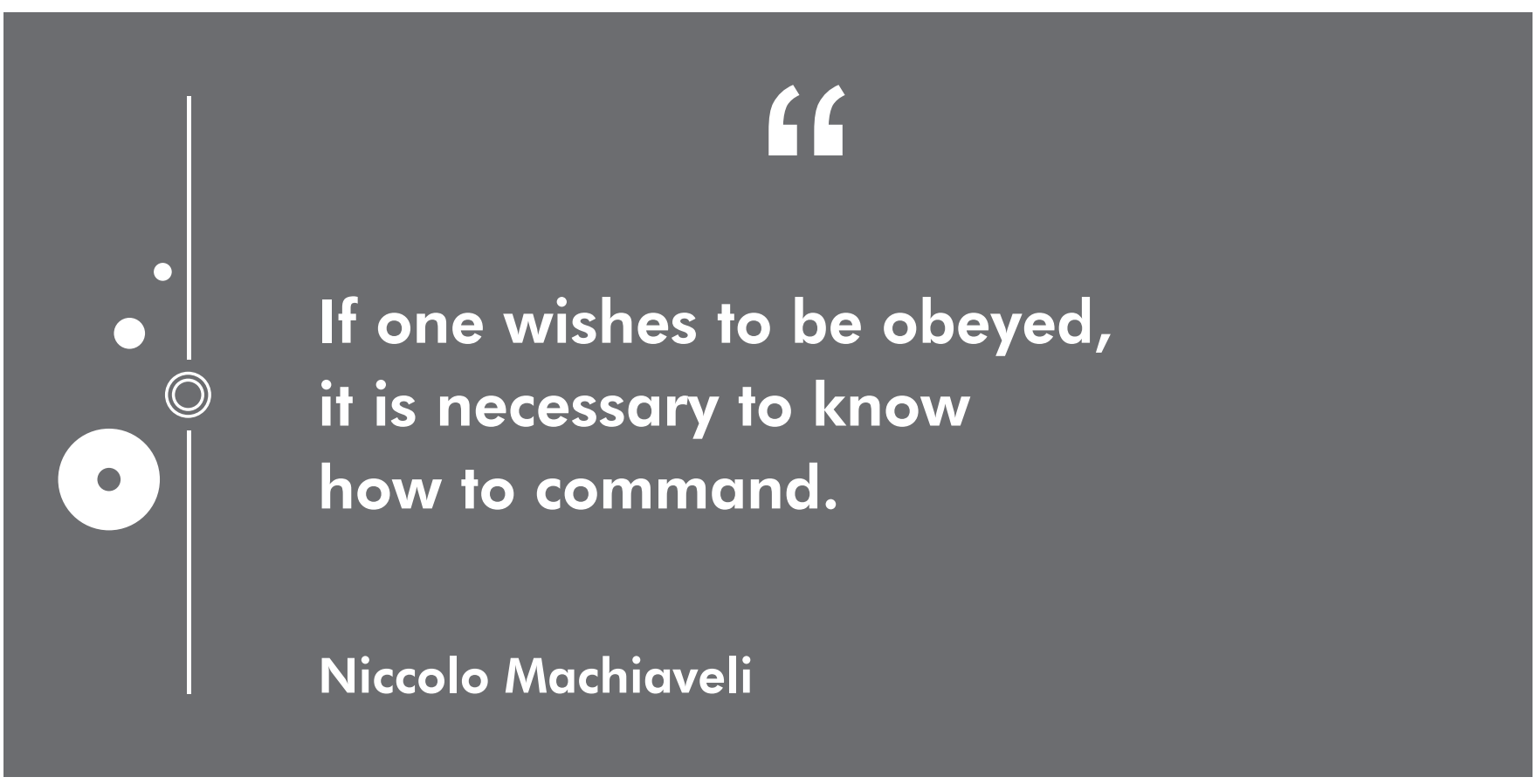

\section{AUTHORSHIP AND CONTRIBUTION DECLARATION}

\begin{tabular}{|c|c|c|c|}
\hline No. & Author(s) Full Name & Contribution to the paper & Author(s) Signature \\
\hline 1 & Zerwah M. Qayum & $\begin{array}{l}\text { Concept, design, data collection, } \\
\text { analysis, interpretation of data, } \\
\text { drafting. }\end{array}$ & \\
\hline 2 & Aftab Hussain & $\begin{array}{l}\text { Concept, design, data collection, } \\
\text { analysis, interpretation of data, } \\
\text { drafting. }\end{array}$ & \\
\hline 3 & Muhammad Akram & $\begin{array}{l}\text { Design, Analysis, Interpretation of } \\
\text { data, Drafting. }\end{array}$ & \\
\hline 4 & M. Asif Saleem & $\begin{array}{l}\text { Data collection, analysis, } \\
\text { interpretation of data drafting. }\end{array}$ & \\
\hline 5 & Rehana Feroze & $\begin{array}{l}\text { Data collection, analysis, } \\
\text { interpretation of data drafting. }\end{array}$ & \\
\hline 6 & Faisal Wahid & $\begin{array}{l}\text { Concept, design, analysis, } \\
\text { interpretation of data, drafting. }\end{array}$ & \\
\hline
\end{tabular}

